\title{
The oxygen fugacity of sublithospheric diamond formation and the conditions encountered during their ascent to the surface
}

\author{
CATERINA MELAI, DANIEL FROST, TIZIANA BOFFA \\ BALLARAN AND CATHERINE MCCAMMON
}

University of Bayreuth

Presenting Author: caterina.melai@uni-bayreuth.de

The rocks-salt structured $\mathrm{Mg}$-Fe oxide, ferropericlase, is one of the more common minerals included in sub-lithospheric diamonds, where it appears in a wide range of $\mathrm{Fe} /(\mathrm{Fe}+\mathrm{Mg})$ ratios.It is important to be able to understand the formation conditions of such inclusions as they provide some of the only direct evidence for the passage of carbon bearing fluids and melts in the deep mantle.In several TEM investigations, exsolution of $\mathrm{Fe}^{3+}$-rich phases,normally described as being part of the magnetite-magnesioferrite solid solution,have been identified within such ferropericlase inclusions. Their presence indicates changing conditions after entrapment and by understanding the exsolution processes we can potentially obtain information on the post entrapment conditions experienced by the diamonds.The ferric iron content of the entire inclusion before exsolution also provides information on the oxygen fugacity $\left(f \mathrm{O}_{2}\right)$ at which the diamond was formed and potentially the medium from which it formed.

To interpret this information, a model for the ferric iron content of ferropericlase as a function of $\mathrm{MgO}$ content,P,T and $\mathrm{fO}_{2}$ conditions up to those where exsolution of $\mathrm{Fe}_{2} \mathrm{O}_{3}$-rich phases occurs, is required. In this work multianvil experiments were performed between 6-25 $\mathrm{GPa}$ and $1200-1800^{\circ} \mathrm{C}$ using a starting composition of $\left(\mathrm{Mg}_{86} \mathrm{Fe}_{14}\right) \mathrm{O}$ to $\left(\mathrm{Mg}_{5} \mathrm{Fe}_{95}\right) \mathrm{O}$ plus varying amounts of $\mathrm{Fe}_{2} \mathrm{O}_{3}$ Pt powder was added to act as a redox sensor and minor amounts of $\mathrm{Ni}, \mathrm{Cr}, \mathrm{Mn}$ and $\mathrm{Na}$ were also added. Samples were then analysed using scanning electron microscopy,electron microprobe, Mössbauer spectroscopy and $\mathrm{X}$-ray diffraction.

In the recovered experiments,ferropericlase was found to coexist with magnetite-magnesioferrite solid solution up to 12 $\mathrm{GPa}$ and $\mathrm{Mg}_{2} \mathrm{Fe}_{2} \mathrm{O}_{5}-\mathrm{Fe}_{4} \mathrm{O}_{5}$ solid solution at higher pressures. In all experiments the oxygen fugacities were determined from three different equilibria simultaneously, and in the calculation of the $f \mathrm{O}_{2}$ a ferropericlase model in the $\mathrm{FeO}-\mathrm{Fe}_{2 / 3} \mathrm{O}-\mathrm{MgO}$ system was employed and exchange of $\mathrm{Mg}-\mathrm{Fe}^{2+}$ in magnetite, or the higher-pressure phase, was accounted for.

The results show that magnetite-magnesioferrite solid solution should not be in equilibrium with ferropericlase in the diamond stability field as the oxygen fugacity would be too high. Our results imply that the exsolution of $\mathrm{Fe}^{3+}$ rich phases observed in natural samples likely occurred at pressures corresponding to the transition zone or deeper. 